\title{
SUBSÍDIOS TEÓRICOS E REFLEXIVOS SOBRE A RELAÇÃO FAMÍLIA-ESCOLA NO CONTEXTO EDUCACIONAL BRASILEIRO
}

\author{
Vivian da Silva LOBATO ${ }^{1}$ \\ FAECS/Campus Universitário de Abaetetuba/UFPA \\ vivianlobato@ufpa.br \\ Graciete Costa dos SANTOS ${ }^{2}$ \\ grasantosatm@hotmail.com
}

Resumo: O presente artigo, intitulado "Subsídios Teóricos e Reflexivos sobre a Relação Família-Escola no Contexto Educacional Brasileiro", foi elaborado a partir dos resultados de um trabalho de conclusão do curso de Pedagogia, os quais desencadearam a busca de reflexões pertinentes à temática do trabalho. Para fundamentar as discussões objetivou-se por meio desse trabalho o seguinte: analisar a partir de estudos teóricos o contexto que envolve a relação famíliaescola nos dias atuais no contexto educacional brasileiro. Optou-se por realizar uma pesquisa bibliográfica, cuja dimensão permitiu que as leituras pudessem servir de bases para a construção de conhecimentos voltados ao foco do trabalho. Por fim, os resultados apontaram que a relação família-escola deve fazer parte de uma das diretrizes que desencadeiam a proposta pedagógica da escola, visando assim oportunizar à criança, ao jovem e ao adulto participarem ativamente do processo ensino aprendizagem resultado da participação familiar junto à escola durante a vida escolar.

Palavras-chave: Escola. Família. Valores. Aprendizagem.

Abstract: This article entitled 'Theoretical and Reflective Subsidies on Family-School Relationship in Brazilian Educational Context', was drawn from academic inquiry, which triggered the search for reflections relevant to the theme of the work. To base their discussions aimed to work through this as follows: to analyze

\footnotetext{
${ }^{1}$ Professora Adjunta da Faculdade de Educação e Ciências Sociais da UFPA Campus de Abaetetuba. Doutora em Educação: Psicologia da Educação. E-mail: vivianlobato@ufpa.br

${ }^{2}$ Pedagoga. Concluiu o curso pela Faculdade de Educação e Ciências Sociais da UFPA - Campus de Abaetetuba. E-mail: grasantosatm@hotmail.com
} 


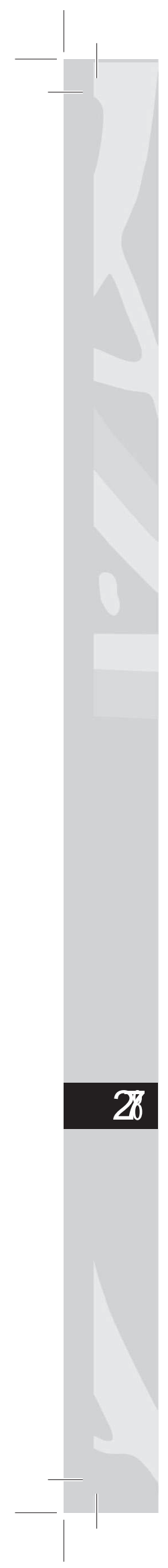

from theoretical context that involves the family-school relationship nowadays the Brazilian educational context. We chose to conduct a literature search, the dimension of which allowed readings could serve as bases for the construction of knowledge aimed at the focus of the work. Finally, the results indicated that the family-school relationship should be part of one of the guidelines that trigger pedagogical school, thus aiming to nurture the children, young people and adults participate actively in the learning process resulted from participation by the family school during school life.

Keywords: School. Family. Values. Learning.

\section{Introdução}

A família representa para a sociedade o lócus de formação inicial para a vida dos seres humanos. Todavia, as mudanças ocorridas no campo dos valores humanos, sociais, culturais, econômicos e políticos têm fragilizado o contexto familiar.

Nos dias atuais, a convivência familiar tem sido afetada pela da necessidade produtividade ou da sobrevivência, posto que os pais ou responsáveis pelo sustento das crianças saem para trabalhar e deixam suas famílias a mercê das informações que a televisão, o rádio ou mesmo a vizinhança têm a oferecer.

No que concerne às divisões de responsabilidades com a educação, encontram-se inserida família e escola. Assim, torna-se fundamental dizer que os debates e as discussões sobre a relação família-escola devem compor o universo acadêmico, visando, com isso, fomentar os debates acerca do processo de internalização das bases que envolvem a educação escolar nos dias atuais a partir da compreensão de que a família é ponto de partida para que a escola exerça sua função social por meio do processo ensino aprendizagem.

Buscando referendar tais reflexões, o presente trabalho foi elaborado a partir dos seguintes questionamentos: Qual a importância de a família participar do processo educativo escolar nos dias atuais? Por que a relação família-escola precisa ser alicerçada por meio da prática de valores sociais, afetivos, humanos, culturais e educacionais? Assim, o objetivo geral é analisar, a partir de estudos 
teóricos, o contexto que envolve a relação família-escola nos dias atuais no contexto educacional brasileiro.

Como forma ainda de subsidiar as discussões, optou-se por realizar uma pesquisa bibliográfica, a qual, segundo Ludke e André (1986), amplia o campo de investigação, haja vista o pesquisador tem como aporte várias leituras e faz delas fonte de argumentação durante a elaboração de seu trabalho. Dessa maneira, é válido citar que as reflexões nasceram fomentadas pelas concepções de: Osório (1996), Sarti (2002), Paiva (2002) Szymanski, (2002), Silva (2008), Freire (1987), Libâneo (2001), entre outros citados no corpo do trabalho.

\section{Relação família-escola: um breve perfil da família brasileira nos dias atuais}

Analisando o perfil das famílias brasileiras, será possível perceber que nos dias atuais existem diferentes famílias, resultado das transformações que ocorreram nos últimos séculos. No Brasil, por exemplo, há famílias que se diferenciam pela diversidade cultural, religiosa, econômica e social.

A miscigenação da população resultou também na formação de famílias com práticas de valores distintos, além do mais, devido à diferença de classes sociais (classe baixa, média e alta), os valores sociais também se tornaram diversificados.

As influências entre os povos (índios, caboclo, negro e imigrantes) na sociedade brasileira foram constituintes dos padrões familiares. Inclusive a influência do processo de colonização criou vínculos familiares hierárquicos, que perduram por décadas como o modelo mais apropriado de família. As famílias do tipo patriarcal perduraram e ainda perduram com alguns resquícios na sociedade brasileira.

Sem sombra de dúvida, a pluralidade cultural no contexto brasileiro, historicamente, desencadeou na relação família-escola especificidades conjunturais. Nos dias atuais, é fácil notar, por exemplo: "[...] o filho do primeiro casamento de sua mãe com a filha

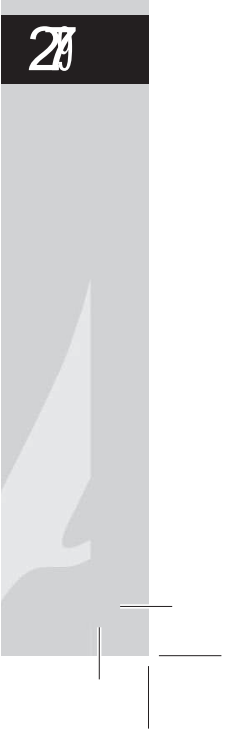




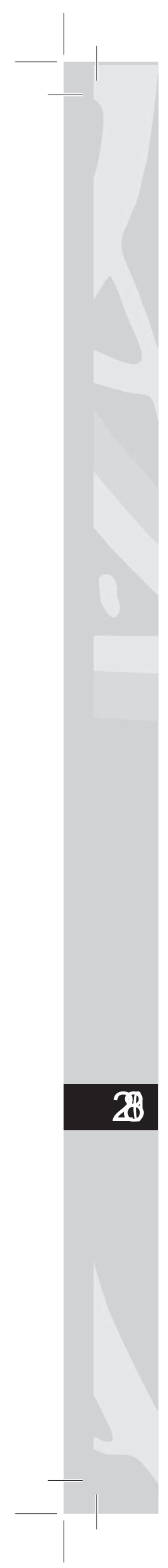

do casamento anterior do atual companheiro de sua mãe" (OSÓRIO, 1996, p. 57).

Neste sentido, é bom lembrar que dentre as muitas formas de conceber a família nos dias atuais, pode-se dizer que a própria conjuntura econômica e política criaram outros laços familiares. $\mathrm{O}$ desemprego, a miséria, a crise de valores ideológicos, religiosos e éticos também têm criado novos horizontes com relação à estrutura das famílias brasileiras. Dentre outras coisas, este processo tem levado as mulheres a assumirem também o papel de responsáveis pela organização familiar, inclusive a econômica.

Está claro que ocorre na sociedade brasileira fenômenos mais ou menos recorrentes em processos de industrialização/urbanização, tal qual em outras formações sociais, na passagem à modernidade. Neste particular, a constituição no mercado de trabalho capitalista e a inserção/exclusão das mulheres neste contexto produziram efeitos sobre a estrutura familiar (OSÓRIO, 1996, p. 43).

Nessa estrutura familiar os papéis sociais ganharam novas configurações. São configurações que quebraram as amarras do machismo. Até muitas décadas atrás, somente o homem podia trabalhar e era o único responsável pelo sustento familiar. Entretanto, as comunidades e os diversos mercados de trabalho veem na mulher um sinal de produção, ou melhor, a mulher também é capaz de assumir responsabilidades no mercado de trabalho.

A família contemporânea no Brasil passa por transformações, as mudanças na relação do sexo masculino com o feminino têm sido afetadas pela formação de valores. No caso das famílias não-nucleares, não é muito diferente, as crianças também são deixadas em casa ou nas creches e escolas. Os aspectos que compõem a diversidade social atingem a família, traçando preâmbulos de grande relevância para o desenvolvimento da afetividade entre e com os componentes familiares. 
As famílias pertencentes à classe social mais baixa são as que mais sofrem com as desigualdades econômicas e com a crise social. $\mathrm{Na}$ verdade existem fatores nos dias atuais que fazem parte da família brasileira, reflexo do próprio modelo de sociedade contemporânea. Se as famílias estão se desestruturando de maneira acelerada, logo a relação família-escola fica também fragilizada.

Segundo Paiva (2002) a desigualdade econômica é o que mais afeta a educação escolar, desembocando também em problemas familiares. Vale ressaltar que algumas famílias sofrem mais do que as outras, por exemplo, "[...] as famílias das classes populares estão no banco dos réus e fornecem explicações simplistas para a exploração contínua de violência que tem marcado a vida social brasileira" (MELLO, 2002, p. 52), portanto as famílias se desestruturam e, ao mesmo tempo, buscam novas formas de se agruparem e de se relacionarem.

Cabe dizer então que as diferenças sociais, a crise econômica e os conflitos internos, sejam pela própria forma de criar a identidade familiar ou não, têm sido a marca registrada do perfil da família brasileira nos dias atuais.

Diante deste aspecto é válido acentuar aqui que o perfil da família nos dias atuais no Brasil, passa por um processo de afirmação perante as exigências da sociedade contemporânea.

\section{Família e escola: instituições que educam para cidadania}

Exercer a cidadania exige do indivíduo a prática de valores, sendo que eles devem estar vinculados a uma formação pessoal e social, inicialmente dentro do ambiente familiar. A relação de afeto, troca e descoberta de sentimentos são os primeiros valores que devem ser construídos no ambiente familiar. Enquanto que na escola, segundo Paiva (2002), as relações sociais perpassam pela necessidade de compreender os conhecimentos científicos atrelados aos conhecimentos adquiridos por meio da convivência familiar. As 


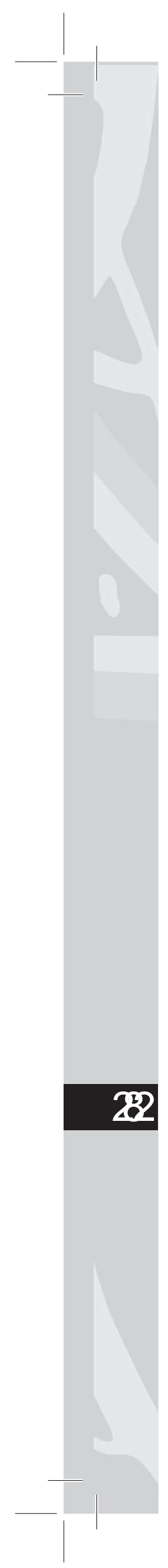

consequências da ausência de uma educação fundada em princípios e valores éticos e pessoais no meio familiar podem resultar numa educação conflituosa na escola.

No ambiente familiar, a comunicação coletiva facilitará ou não a negociação, a aproximação do sentimento de pertencimento entre os entes familiares. A construção de relações de empatia social e pessoal, permitida por meio da escuta, depende muito da intensidade e da qualidade dessa comunicação positiva. Discutir sobre a real função que a família e a escola têm com relação à organização e à propagação dos princípios sociais que modelam a boa convivência cidadã, requer dos educadores tornarem-se mediadores na construção de valores impregnados de afetividade.

A educação para cidadania, de acordo com Freire (1999), não ocorre somente por conta de que as pessoas precisam se educar para conviver socialmente, mas para que isso ocorra primeiramente é preciso deixar claro que a escola, como lugar educativo, tem uma função abrangente, mesmo porque:

\begin{abstract}
O respeito à autonomia e à dignidade de cada um é o imperativo ético e não um favor que podemos ou não conceder uns aos outros. Precisamente porque éticos podemos desrespeitar a rigorosidade da ética e revelar para sua negação, por isso é imprescindivel deixar claro que a possibilidade do desvio ético não pode receber outra designação senão a de transgressão (FREIRE, 1999, p. 66).
\end{abstract}

Diante desse fato, pressupõe-se dizer então que a educação para cidadania é parte integrante da formação humana e que a família e a escola são instituições que podem veicular por diversas formas de práticas sociais ligadas ao exercício da cidadania. Se na família são trabalhados valores existenciais à vida dos seus membros, na escola também deve haver sistematização de processos educativos voltados à educação de pessoas, de forma que elas possam compreender que tanto os conhecimentos compartilhados no ambiente familiar quanto 
os conhecimentos escolares constituem um legado prático de vida, de sobrevivência social.

Sobre este aspecto Paiva (2002, p. 9), afirma que: "A responsabilidade da escola nos tempos atuais é preparar o aluno para uma vida ordenada do universo, em que o educando possa encontrar seu lugar no mundo". Dessa forma, educar para cidadania exige compreensão da realidade social, cultural e econômica da qual as crianças, os jovens ou os adultos fazem parte. Os sujeitos fazem parte de um conjunto globalizado de intenções previamente socializadas. Assim:

A escola hoje, não pode viver isolada, achando que todos cumprem o seu papel. A escola, antes, é o espaço problematizador, criador, mediador. Ela está mais próxima da família que estabelece como parceria, dividindo responsabilidades (PAIVA, 2002, p. 9).

Dessa maneira a cidadania deve ser mecanismo de descoberta, uma vez que a sala de aula ganha destaque, já que nesse local as pessoas trocam experiências, aprendem valores, praticam simbolicamente a comunicação linguística histórica e culturalmente transformada. A escola deve ser aliada da família no processo educativo formal, necessário ao exercício da cidadania. Trata-se de objetivos comuns, cuja meta maior é a de educar para a vida, para o desempenho social.

No atual quadro social brasileiro, falar de cidadania corresponde a algo necessário. De acordo com Arroyo (2007), a escola e a família são pontes que se encontram inseridas de uma dinâmica contextual relevante frente as mudanças que ocorrem de forma acelerada, tanto no contexto escolar quanto no espaço familiar. Os múltiplos olhares que devem ser lançados com relação à função social de cada instituição tende transitar por caminhos ainda conturbados, segundo o autor; já a crise social (violência doméstica tanto entre os pais quanto deles com os filhos) é um fator que tem deixado escola e família, de certa forma, perdidas. 
Se o papel da escola no campo social é educar para cidadania, o da família é fazer o possível para que as crianças ou os jovens sejam parte integrante de projetos pessoais e sociais a partir da convivência familiar. São processos diferentes que ocorrem em ambas as instituições, porém, tanto no espaço familiar quanto no escolar a educação ocorre.

Freire (1996), ao falar da cidadania, enfatiza que o homem não é um ser estático, mas um ser em movimento, justamente por conta de ele usar a razão para entender o seu mundo e o mundo que o cerca. Para o autor, a educação leva o homem a exercer sua cidadania de maneira dinâmica, e esta é construída pelos elos que se formam por meio da confiança estabelecida entre os sujeitos e deste com o mundo. Uma vez que:

A confiança vai fazendo os sujeitos dialógicos cada vez mais companheiros na proníncia do mundo... A confiança implica o testemunho que um sujeito dá aos outros de suas reais e concretas intenções. Não pode existir, se a palavra, descaracterizada, não coincide com os atos (FREIRE, 1987, p. 82).

Szymanski (2001) comenta que tanto a escola quanto a família precisam ser analisadas a partir da importância que cada uma tem no universo educativo e prático que envolve a vida dos seres humanos, pois:

O que ambas as instituições têm em comum é o fato de prepararem os membros jovens para o desempenho de funções que possibilitem a continuidade da vida social. Ambas desempenham um papel importante na formação do indivíduo e do futuro cidadão (p. 62).

$\mathrm{Na}$ visão da autora, o que existe em comum entre a relação família e escola corresponde, em especial, às múltiplas formas de educar e ser educado, já que, segundo Freire (1987), o homem se educa mediatizado pelo próprio mundo, particularmente a partir da intervenção da realidade de que faz parte. A dimensão formativa que 
as duas instituições têm em comum é justamente garantir a existência de pontos ligados à educação cidadã das pessoas, haja vista as práticas sociais são mecanismos sociáveis que precisam ser compartilhados tanto na família quanto na escola.

Legalmente a educação deve promover o exercício da cidadania, tendo como norte o que a Constituição Federal deixa claro, como direito legal, haja vista no Brasil o dever da educação não garante direitos, mas é garantida como direito público. Afirmação esta estabelecida no artigo 205, o qual explicita que:

Art. 205: A educação, direito de todos é dever do Estado e da família, será promovida e incentivada com a colaboração da sociedade, visando ao pleno desenvolvimento da pessoa, seu preparo para o exercício da cidadania e sua qualificação para o trabalho (BRASIL 1988, p. 137).

Como se pode observar, legalmente, a educação é um direito fundamental para o exercício da cidadania no contexto brasileiro. Assim, o ponto de partida para que a escola se torne local formador e de formação cidadã passa pela possibilidade de os sujeitos vivenciarem aprendizagens coletivas socializadas e praticadas também de forma individual. Neste caso a função social de cada instituição não corresponde somente pela garantia do aspecto legal que ambas as instituições têm a cumprir, mas pelo fato de haver propósitos existenciais com relação à educação formal, dada pela escola e a educação não-formal, dada pela família.

A socialização e a formação de valores pessoais, culturais, econômicos e políticos servem de subsídios para os indivíduos, tendo em vista que eles compartilham experiência no mundo, na sociedade que estão inseridos. A família, como instituição em movimento, tem sido vista num processo evolutivo. Necessariamente: "[...] a família insere-se num contexto evolutivo e possui seu ciclo vital, [...] a família também nasce, cresce, amadurece, habitualmente se reproduz em novas famílias...” (OSÓRIO, 1997, p. 22). 


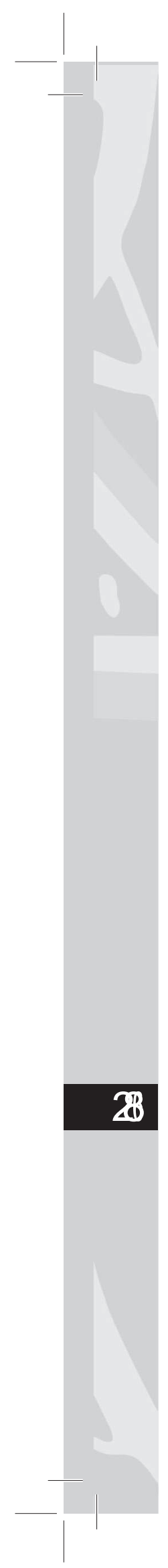

Esse processo vai além do fato de que a família tem somente papéis a cumprir, diz respeito a sua abrangência educativa, cujo desempenho de funções e atribuições educativas passam pela ação de educar para a vida. No campo legal é claro que a família tem sua obrigação com a educação da criança ou do jovem. Porém, como bem afirma Libâneo (2001), a educação escolar tem visto na família um caminho que precisa ser construído pelo estreitamento de relações mais próximas possíveis.

A escola, entretanto, ao promover o exercício da cidadania, não deve e não pode ver a família como uma instituição essencialmente responsável pelos atos irresponsáveis dos sujeitos. Para tanto, os cuidados com a sistematização das ações na escola requer mais atenção e preparação nos seus diversos aspectos. Os educadores, por sua vez, não podem se eximir de cobrar da família a responsabilidade familiar como instituição capaz de atuar à frente de problemas emocionais que os sujeitos trazem para a escola.

É necessário exercitar a cidadania por meio dos movimentos que a escola oferta na busca de trazer a família como parceira. Um dos meios viáveis que eleva a participação democrática da família na educação é o fato de que cidadania não se compra, mas se vive e se pratica. Como bem ressalta Freire (1987), educação é um movimento que tem seus próprios elementos, os quais requerem dos educadores participação e intenções previamente planejadas.

Se o modelo de família não atende a todos os requisitos ou mesmo se a escola não consegue cumprir com seu papel, ainda assim ambas as instituições devem ser vistas como espaço educativo de grande importância para a vida dos seres humanos. Esta é uma das características que mais precisam ser lembradas, tanto pela família quanto pela escola, objetivando, com isso, tornar, ambos os espaços, lugares educativos em constante transformação.

\section{Espaço educativo em contínua construção a partir da contribuição da família}

As dificuldades de aprendizagem que surgem no contexto escolar tendem a ser levada para fora da escola, ou seja, a família 
também é acessada pelos educadores, visando, com isso, debater ou solucionar os problemas de aprendizagem. Os vários fatores que interferem na aprendizagem, além de problemas de atenção, concentração e indisciplina, podem ter ligação também com os conflitos familiares. Neste caso, a participação da família se torna necessária, pois constitui um processo que exige acompanhamento contínuo do andamento dos sujeitos na escola.

Paiva (2002) declara que cada vez mais ocorre incidência de crianças que apresentam algum comportamento de violência, indisciplina ou apatia no interior das escolas. Isso tem repercutido negativamente na vida escolar dos sujeitos, tendo em vista que eles acabam sendo colocados como alunos-problema pela instituição escolar. Sendo então problema, a família passa a ser alvo de questionamento e de análise dos educadores e das autoridades responsáveis pela educação na sociedade.

Neste sentido, Paiva (2002) esclarece que é preciso criar meios de estreitar a relação família-escola, haja vista tais instituições serem responsáveis pela educação dos indivíduos. Sendo assim, é quase natural cobrar da escola ações voltadas à aproximação da família ao processo ensino aprendizagem. A autora coloca em evidência, inclusive, que é preciso haver o encontro permanente entre as duas instituições, não só para cobrar favores ou responsabilidades, mas ratificar a qualidade da educação a ser dada aos sujeitos. Acredita-se que:

É nesse encontro: escola-aluno-família, que se pode construir uma relação de troca, de complementaridade que possibilita a todos, se educarem e serem educados. Quando isso acontece, o aluno que está sendo educado também passa a ser educador. Além disso, o educador deve ser cidadão consciente, possuidor de uma visão crítica do mundo (ou de si), para poder propor situações de aprendizagem para a vida, com base em princípios e valores: éticos, morais e religiosos (idem, 2002, p. 9).

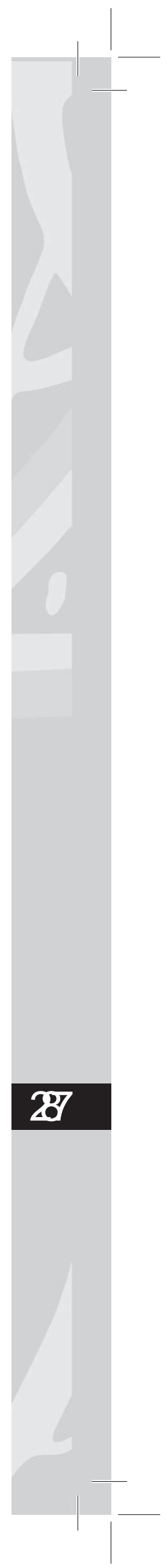




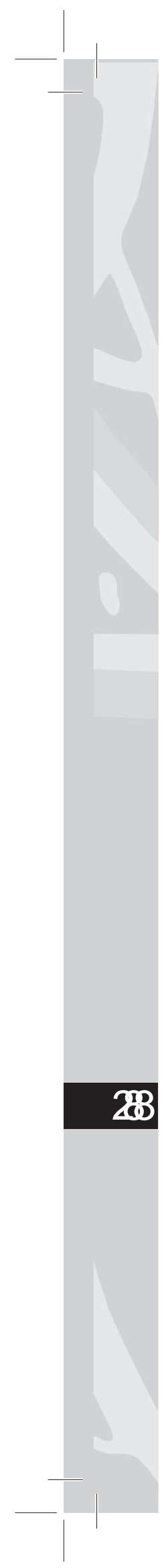

Se a escola tentar resolver os conflitos isoladamente, corre o risco de não avançar nas negociações quanto à busca de resolver os problemas. Sem ajuda da família, não conseguirá atender às necessidades dos alunos, e, se a família se eximir da responsabilidade de acompanhar a educação dos sujeitos, também a escola corre o risco de não conseguir suprir essa ausência. Outro ponto que convém destacar aqui se refere ao fato de a escola ter que cumprir todo um calendário, currículo e planejamento em função de promover aos sujeitos o acesso ao conhecimento mais sistematizado.

O modelo de família faz parte da política neoliberal instalada em muitas sociedades, inclusive no Brasil. É um precedente que vem demarcando o papel do homem e da mulher na sociedade contemporânea. Esse aspecto caracteriza que a escola, como lugar educativo, tem sua extensão ligada à própria conjuntura que envolve a lógica de mercado neoliberal. As novas experiências de tipos de família que estão surgindo no panorama social atualmente favorecem a individualidade dos componentes familiares, logo, favorece o distanciamento da instituição família da escola.

A família pertencente à classe pobre, segundo Paiva (2002), tem enfrentado grandes tragédias, que vão desde a violência social até a ausência de assistência à vida digna, tão importante para a sobrevivência humana. Desse modo, os membros que fazem parte desse tipo de família acabam vivenciando a crise existencial quanto à sua verdadeira identidade na sociedade como instituição social. Uma vez que os papéis são maleáveis, sofrem com as consequências da pobreza, da violência e do descaso do poder público. No Brasil, conforme reflexões de Arroyo (2007), é unânime a publicação de grandes tragédias na mídia envolvendo componentes familiares de classe baixa.

A ausência de reciprocidade no ambiente familiar fragiliza o ambiente escolar. Os laços afetivos se distanciam uns dos outros causando traumas nas crianças, as quais, ao se tornarem adultas, acabam por vivenciar os mesmos hábitos já vividos inicialmente na sua família de origem paterna e materna. Szymanski (2001) destaca 
que a família idealizada a partir do modelo tradicional perdeu suas características originais, tendo em vista que as mudanças têm acelerado a constituição de novos modelos de família nas sociedades, inclusive na brasileira.

Vale ressaltar que a família tem sua parcela de contribuição no processo educativo formal, dado que, inicialmente, é ela que provê os primeiros conhecimentos a serem concebidos pelos sujeitos. A escola é essencialmente um espaço importante para a convivência de valores, de assistência afetiva, social e psicológica, mas as mudanças que vêm ocorrendo na sociedade atualmente têm provocado distanciamento de suas responsabilidades escolares.

Contudo, nem por isso a escola tem que ocupar o lugar da família e vice-versa. As duas têm maneiras diferentes de proporcionar a formação social e individual às pessoas, mesmo que isso pareça piegas. Na verdade a ajuda mútua no grupo família ainda é um laço que necessita ser ampliado, visando com isso fortalecer as bases educativas que a escola tem que ofertar aos indivíduos. Manter esta estabilidade é um desafio para os educadores, diz respeito à construção de etapas na relação família-escola.

Durante a infância, os sujeitos devem vivenciar momentos que lhes proporcione a descoberta de valores, e isso a família deve ofertar a eles. Já na escola, os sujeitos deveriam ser acompanhados pela família, buscando, com isso, afirmar-se socialmente no meio ao qual fazem parte. Partindo dessa ótica, verifica-se que a escola, na condição autônoma e democrática, é um lugar educativo de grande relevância para a sociedade, mesmo que seja um espaço privado público, cabe a ela trabalhar também a propagação de regras, limites e valores existenciais a vida humana.

No Brasil, a educação tem no Conselho Escolar uma forma de integrar a família dentro da escola, pois os pais escolhem um representante para compor o conselho por meio da realização de assembleia geral, com a participação dos pais e responsáveis dos alunos. Segundo observações empíricas, algumas realidades já existem momentos mais dinâmicos da relação família e escola. 
Uma conversa franca dos professores com os pais, em reuniões simples, organizadas, onde é permitido aos pais falarem e opinarem sobre todos os assuntos será de grande valia na tentativa de entender melhor os filhos/ alunos. A construção desta parceria deveria partir dos professores, visando, com a proximidade dos pais na escola, que a família esteja cada vez mais preparada para ajudar seus filhos. Muitas famílias sentem-se impotentes ao receberem, em suas mãos os problemas de seus filhos que the são passados pelos professores, não estão prontas para isso (SILVA, 2008, p. 1).

Desse modo, é válido que a manutenção da relação famíliaescola, na sociedade contemporânea, como instituição educativa, tem que ser gerada pela autonomia que cada uma possui. Com relação à cobrança que a escola muitas vezes pratica frente a ausência de participação da família à frente do processo ensino aprendizagem, convém dizer que isso é um fato preocupante, porém não é impossível de se resolver. A organização do processo educativo tem que estar alinhada a propostas de trabalho que vise oportunizar aos sujeitos, por meio do processo de aprendizagem, a compreensão da realidade.

Além disso, a escola não deve ser só um lugar de aprendizagem, mas também um campo de ação no qual haverá continuidade da vida afetiva. $A$ escola que funciona como quintal da casa poderá desempenhar o papel de parceira na formação de um indivíduo inteiro e sadio. É na escola que deve se conscientizar a respeito dos problemas do planeta: destruição do meio ambiente, desvalorização de grupos menos favorecidos economicamente, etc. (SILVA, 2008, p. 1).

A relação escola-família, nos dias atuais, vem sendo construída por muitos caminhos, um deles é a cobrança, de ambas as partes, da criação de melhorias na vida escolar de crianças e adolescentes. Essa é uma razão para dizermos que a qualidade da educação escolar 
atualmente pode ser cobrada pela família a partir da cobrança que as leis permitem executar, como a Constituição Federal (1988), Estatuto da Criança e do Adolescentes (1990) e LDB 9.394/96. Esses documentos são instrumentos legais que existem para estreitar as relações entre as duas instituições.

As escolas públicas no Brasil têm muitas fragilidades por conta da falta de investimentos do poder público, porém, propostas com iniciativas que visam melhorar a educação escolar são propagadas na mídia brasileira. Dessa forma, a escola tem que cumprir sua função social frente as cobranças de pais e responsáveis. Nesse sentido, convém citar que atualmente vem sendo criado um novo cenário na educação brasileira com o propósito de trazer, o mais rápido possível, as famílias para o contexto escolar, visando assim articular com efetividade o compromisso que elas possuem com a formação dos sujeitos.

E a escola, para atender à cobrança da família, deve ter como parâmetro um processo de ensino-aprendizagem, trabalhando de forma planejada e articulada com as bases na formação integral dos sujeitos, mas para que isso aconteça, antes de tudo, o professor tem que conhecer a realidade do aluno. Por meio do conhecimento real acerca da estrutura que envolve a vida do aluno, o professor pode organizar seu trabalho. Tal dinâmica tende a contribuir para que as responsabilidades mútuas a serem praticadas pela escola e pela família sejam partilhadas com fins pedagógicos, sociais e pessoais. Cada família tem sua singularidade, logo a criança traz para a escola significados singulares relacionados ao seu ambiente familiar. Assim:

Tudo o que ocorre numa família tem um significado. Nossas ações refletem novos modos de pensar, nossos sentimentos, nossas ambiguidades, nossas possibilidades no momento, nossas limitações. Exemplificando: a escolha do lugar à mesa, o tempo que cada um recebe para falar é uma manifestação de hierarquia, a divisão de tarefas e sua efetiva realização como um envolvimento com o cotidiano

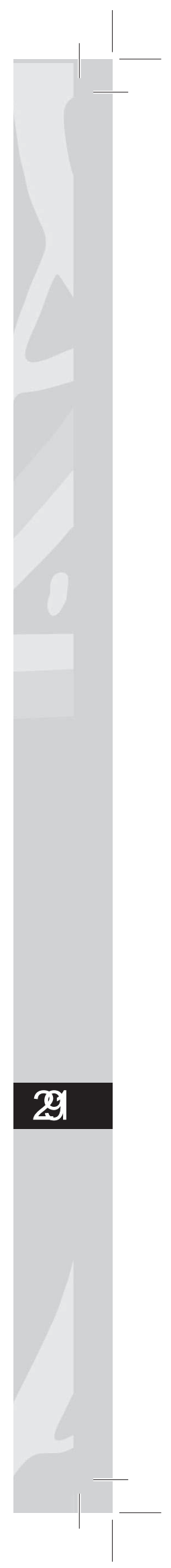


familiar e respeito entre os membros da família (SZYMANSKI, 2001, p. 49).

No cotidiano da escola, torna-se necessário que o professor estabeleça mecanismos de aprendizagem, e caso ele perceba que seus alunos estejam com problemas emocionais e de aprendizagem, torna-se fundamental que a escola, planeje ações voltadas a resolver os problemas com os alunos com a contribuição da família. Paiva (2002) destaca que é uma questão fundamental a conversação entre família e escola. Uma vez tomadas medidas mais adequadas às necessidades dos alunos, as contribuições perceptivas da família junto ao processo ensino-aprendizagem tendem a surtirem efeitos mais amplos à vida dos sujeitos.

A aproximação da família com a escola é fundamental para que problemas, como violência, agressividade e desconcentração, vivenciados por muitos alunos, em nível de Brasil, não sejam vistos pela família e pelos educadores como obstáculos, e sim como problemas solucionáveis. Dessa forma, a escola cumprirá seu papel de educadora ampliada e socializada a partir do envolvimento da família na organização pedagógica dos sujeitos, pois:

O dever da família com o processo de escolaridade e a importância da sua presença no contexto escolar é publicamente reconhecido na legislação brasileira e nas Diretrizes do Ministério da Educação aprovadas no decorrer dos anos 90. Algumas destas constatações podem ser verificadas em publicações como o Estatuto da Criança e do Adolescente (ECA), Lei 8.069/90 em seu artigo 205.

Se a escola conseguir trazer para o seu espaço a família, dando a ela o direito de intervir, participar e mediar melhorias do processo ensino-aprendizagem, quem ganhará com isso serão os alunos, sejam eles crianças, adolescentes ou adultos. Tal dinâmica é possível de ser concretizada, mas para isso tanto os educadores como os pais 
têm que se sentar e decidir as bases da educação escolar que deve ser efetivada.

Pode-se dizer que essa é uma das possibilidades que fortalecerá a relação família-escola. A comunicação entre ambas as instituições não pode ser vista apenas como mecanismo de cobrança de responsabilidades de uma ou de outra, mas como mecanismo mediador, formativo e socializador necessário à vida dos seres humanos. Organizar na escola a inclusão de atividades socioeducativas exige planejamento democrático. Tornar a família articuladora do processo ensino-aprendizagem nos dias atuais requer da escola ações de valorização e respeito à individualidade e à singularidade de cada criança, jovem ou adulto. Este é um olhar que precisa ser construído por todos os envolvidos no processo educativo, seja a família ou a escola, pois o mais importante não é dividir deveres e obrigações, e sim construir meios para que os sujeitos tenham a oportunidade de ter apoio tanto na família quanto da escola em sua vida escolar.

\section{Considerações finais}

As instituições sociais, historicamente, têm propiciado à humanidade a construção e a prática de valores, dos quais faz parte a própria formação de princípios que os indivíduos necessitam para se organizar e vivenciar na sociedade a sua socialização. Os papéis sociais que cada instituição tem a cumprir fazem parte da vida humana. No meio social, os seres humanos exercem influências uns no outro. Desse modo, as instituições responsáveis pela formação humana, historicamente, foi e ainda é a família e a escola.

A função social de cada uma tem especificidades singulares, porém é por meio da convivência familiar e escolar que os seres humanos se educam, aprendem regras e valores sociais importantes para aquisição da cidadania. Diante deste aspecto, torna-se fundamental que, após ter realizado um estudo teórico sobre a relação família-escola, conclua-se que a família é o espaço onde os seres humanos aprendem e assimilam os primeiros ensinamentos 


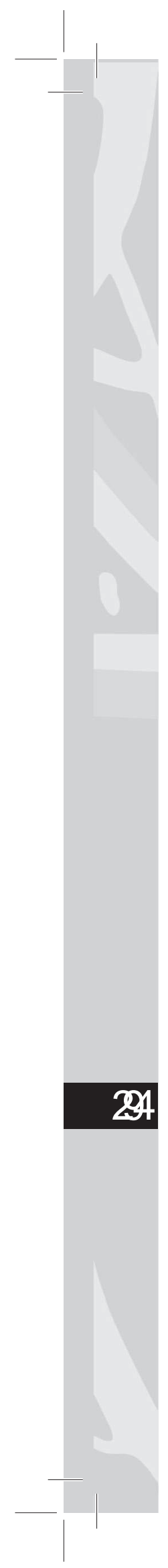

para vida. A escola, por sua vez, precisa ser o espaço de formação/ preparação das novas gerações; é o espaço do futuro, para o qual se necessita de bons professores para fazer avançar a consciência transformadora desse espaço público, permitindo-se mostrar aos alunos que os muros da escola não os separam da vida lá fora, mas sim que, junto com a família, a escola ajuda a prepará-los para enfrentar essa realidade. Portanto, escola e família, juntas, devem ser responsáveis pela educação do indivíduo, em sentido amplo.

Compreender que é dever da família educar os sujeitos e cuidar deles nos seus primeiros momentos de vida, significa dizer que a responsabilidade pela aquisição dos primeiros valores humanos e sociais cabe, primeiramente, à família, bem como possibilitar aos sujeitos a troca desses valores. Quanto à escola, cabe a ela planejar e orientar a aquisição, a assimilação e a prática na sociedade dos conhecimentos elaborados historicamente pela humanidade. Enfim, tanto a escola quanto a família são instituições de múltiplas faces sociais, porém cada uma tem sua singularidade social e institucional. Desse modo, faz-se necessário apontar que, de acordo com as reflexões, debates e discussões pertinentes à temática do trabalho é válido citar, ainda, que a relação família-escola anda muito avessa do que deveria ser.

Necessariamente, a relação família-escola deve fazer parte de uma das diretrizes que desencadeiam a proposta pedagógica da escola, visando, assim, oportunizar à criança, ao jovem e ao adulto participarem ativamente do processo ensino-aprendizagem, resultado da participação familiar junto à escola durante a sua vida escolar. Dessa forma, torna-se fundamental que as discussões não parem no meio acadêmico, mas que avancem para outras dimensões, particularmente dentro da escola, a fim de que os educadores possam ver que a família é um espaço privado, o qual tem suas denominações e particularidades, e que ela tem uma função social própria de sua realidade. E que a escola é um espaço público, o qual tem suas especificidades relacionadas ao coletivo, porque atende à sociedade de maneira geral. Considera-se que essas são percepções valiosas para 
que a relação família-escola ganhe suporte na vida dos alunos, para que eles sejam valorizados, respeitados e principalmente educados, visando ao exercício da cidadania em qualquer tempo e espaço social, independentemente do tipo de família, da cor, da raça ou da classe social a que pertençam.

\section{REFERÊNCIAS}

ARROYO, M. G. Imagens quebradas: trajetórias e tempos de alunos e mestres. $4^{\mathrm{a}}$ ed. Petrópolis: Vozes, 2007.

BRASIL. Lei 9394, de 20 de dezembro de 1996. Brasília: MEC, 1996.

- Parâmetros Curriculares Nacionais: introdução aos Parâmetros Curriculares Nacionais/Secretaria de Educação fundamental. Brasília: MEC/SEF, 1997.

Constituição da República Federativa do Brasil. Brasília, 1988.

FREIRE, Paulo. Pedagogia do Oprimido. $17^{\mathrm{a}}$ edição. Rio de Janeiro: Paz e Terra. 1987.

Pedagogia da Autonomia: saberes necessários à prática educativa. São Paulo: Paz e Terra, 1999.

Pedagogia da esperança. São Paulo: Paz \& Terra, 1987.

LUDKE, Menga: ANDRE, Marli. Pesquisa em educação: abordagem qualitativas. São Paulo: EPU, 1996.

LIBÂNEO, José Carlos. Organização e gestão da escola: teoria e prática. Goiânia: Editora Alternativa, 2001. 
MARTURANO, E.M. et. al.. Crianças com dificuldades escolares: recursos e adversidades na família [Resumo]. XXVI Reunião Anual de Psicologia (p. 117). Ribeirão Preto, 1996.

OSÓRIO, Luiz Carlos. A família hoje. São Paulo: Artes Médicas, 1997.

PAIVA, Sâmara. Educação dos pais e educação da escola. Revistas Mundo Jovem. N. 323, 2002.

SZYMANSK, Heloísa. Teórico e Teoria de família. In: CARVALHO, Maria do Carmo (Org.). A família contemporânea em debate. São Paulo: Editora Cortez, 2002.

SZYMANSK, Heloísa. A relação família escola: desafios e perspectivas. Brasília: Plano Editora, 2001.

SARTI, Cynthia. Família e individualidade: um problema moderno. In: CARVALHO, Maria do Carmo (Org.). A família Contemporânea em debate. São Paulo: Cortez, 2002. 